\title{
Klasik Nonketotik Hiperglisinemi Tanılı Bebekte İlaca Dirençli Epilepsi Tedavisinde Ketojenik Diyet Uygulaması: Bir Olgu Sunumu
}

\author{
Ketogenic Diet Treatment of Drug Resistance Epilepsy in an Infant with Classic Nonketotic \\ Hyperglycinemia
}

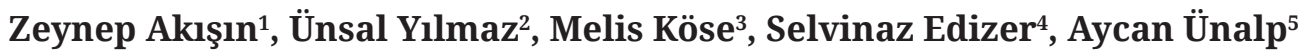

Geliş tarihi/Received: 21.02.2019 • Kabul tarihi/Accepted: 14.04.2019

\section{ÖZET}

Nonketotik hiperglisinemi (NKH), glisin yıkımında görevli bir enzim eksikliğine bağlı otozomal resesif geçiş gösteren bir metabolizma hastalığıdır. Hipotoni, gelişme geriliği ve ilaca dirençli nöbetler ile karakterizedir. Gelişme geriliği ve 45 günlük iken başlayan nöbetler nedeniyle başvuran ve nonketotik hiperglisinemi tanısı alan hastaya yatışının ikinci gününde levetirasetam, dekstrometorfan ve sodyum benzoat tedavisi başlanmıştır. İzlemde fenobarbital eklenmesine karşılık nöbetleri devam eden hastaya ketojenik diyet tedavisi (KDT) başlanması planlanmıştır. Belirgin bir yan etkinin görülmediği hastada, tedavinin üçüncü gününden itibaren nöbet sıklı̆̆ı ve şiddetinde \%50'den fazla azalma görülmüştür. Klasik KDT, antiepileptik ilaçlara dirençli NKH hastalığında etkin ve güvenilir bir tedavi yöntemi olabilir.

Anahtar kelimeler: Nonketotik hiperglisinemi, ketojenik diyet, ilaca dirençli epilepsi

\section{ABSTRACT}

Nonketotic hyperglycinemia (NKH) is an autosomal recessive metabolic disorder caused by an enzyme deficiency which breaks down the amino acid glycine. It is characterized by hypotonia, growth retardation and drug-resistant seizures. The patient presented to our clinic with growth retardation and seizures starting from the 45th days of age. A diagnosis of NKH was made, and levetiracetam, dextromethorphan and sodium benzoate were started in two days after diagnosis. Despite the addition of phenobarbital in the follow-up, the patient continued to have seizures and a ketogenic diet was planned. Frequency and severity of seizures were reduced by more than $50 \%$ at the third day of treatment, and no significant side effects were reported. Classic KDT may be an effective and reliable treatment in NKH patients with drug-resistant seizures.

Keywords: Nonketotic hyperglycinemia, ketogenic diet, drug resistant epilepsy

1. ̇letişim/Correspondence: SBÜ. Dr Behçet Uz Çocuk Hastalıklar ve Cerrahisi Eğitim ve Araştırma Hastanesi, Beslenme ve Diyetetik Bölümü, İzmir, Türkiye

- E-posta: zakisin98@gmail.com

은 https://orcid.org/0000-0002-2865-4810

2. SBÜ. Dr Behçet Uz Çocuk Hastalıklar ve Cerrahisi Eğitim ve Araştırma Hastanesi, Çocuk Nörolojisi Bölümü, İzmir, Türkiye

(ㄱ https://orcid.org/0000-0002-7256-8557

3. SBÜ. Dr Behçet Uz Çocuk Hastalıklar ve Cerrahisi Eğitim ve Araştırma Hastanesi, Çocuk Metabolizma Hastalıkları Bölümü, İzmir, Türkiye

๑) https://orcid.org/0000-0003-2255-3725
4. SBÜ. Dr Behçet Uz Çocuk Hastalıklar ve Cerrahisi Eğitim ve Araştırma Hastanesi, Çocuk Nörolojisi Bölümü, İzmir, Türkiye (1) https://orcid.org/0000-0002-8846-383X

5. SBÜ. Dr Behçet Uz Çocuk Hastalıklar ve Cerrahisi Eğitim ve Araștırma Hastanesi, Çocuk Nörolojisi Bölümü, İzmir, Türkiye

○ https://orcid.org/0000-0002-3611-5059 


\section{GíRiş}

Nonketotik hiperglisinemi (NKH), yeni doğan ve erken süt çocukluğu döneminde ilerleyici seyir gösteren, otozomal resesif geçişli, seyrek görülen bir doğumsal metabolizma hastalığıdır (1). Klasik, şiddetli neonatal NKH hastalarının yaşamlarının ilk döneminde hipotoni, artan laterji, nöbetler, hıçkırıklar, ensefalopati, sıklıkla ve ilerleyen apneler gelişir (2). Şiddetli NKH için etkili bir tedavi mevcut değildir. Glisin düzeylerinin düşürülmesini (sodyum benzoat ve orta derecede protein kisitlanması) ve bunun N-metil-D-aspartat (NMDA) reseptör bölgesinde (dekstrometorfan, ketamin ve felbamat) etkisinin bloke edilmesini amaçlayan tedaviler yenidoğan ciddi NKH'de nöbet kontrolü, solunum ve uyanıklık üzerine etkili olabilir. Bununla birlikte bu tedaviler, zeka geriliği ve spastitesinin gelişmesini önlemez, doğum öncesi ve devam eden postnatal glisin kaynaklı nörotoksisiteyi gösterir (3). Son zamanlarda, küçük bir NKH hasta kohortunda denenen ketojenik diyet, nöbet kontrolünde ve yaşam kalitesinde düzelme olduğunu göstermiştir $(4,5)$.

\section{OLGU SUNUMU}

Yirmi dört yaşında sağlıklı annenin 2. gebeliğinden 2. yaşayan olarak, 38. gestasyon haftasında $3040 \mathrm{~g}$ vücut ağırlığında ve $50 \mathrm{~cm}$ boyunda sezaryen doğum ile doğan ve perinatal dönemde sorun olmayan olgu, 45 günlük iken uykuya meyili ve hıçkırık nöbetleri ile hastanemizin acil servisine başvurmuştur. Glisin ensefalopatisi ön tanısı alan hastaya dekstrometorfan, sodyum benzoat velevetirasetam tedavisi başlanmıştır. Hastanın plazma glisin düzeyi 1035.03 mol/L (normal değer= 111-426 mol/L)'dir. Nöbetleri sıklaşan hasta ileri tetkik ve tedavi amacıyla yoğun bakım ünitesine yatırılmıştır. Hastaya 135 kkal/kg/gün enerji ve 1.0 g/ $\mathrm{kg} / g u ̈ n$ protein içeren diyet tedavisi düzenlenmiştir. Diyet tedavisi, günde 8 öğün 75 mL suya 1.5 ölçek Basic P mama ve 1 ölçek Aptamil 1 mama karışımı verilecek şekilde planlanmıştır (Tablo 1).
Yapılan ileri tetkiklerde $\mathrm{NKH}$ tanısı kesinleşmiştir. Günde 6-7 kez, 1-5 dakika süren hıçkırık ve kasılma nöbetleri görülmekteydi. Uygulanan ilaç tedavisine rağmen hastanın epileptik nöbetlerinin devam etmesi nedeniyle ketojenik diyet tedavisine (KDT) başlama kararı alınmıştır. Ketojenik diyet tedavisi öncesinde, çocuk nörolojisi uzmanı, diyetisyen ve hemşirenin görev aldığı KDT ekibi tarafından hastanın ebeveynlerine diyet konusunda eğitim verilmiştir. Ketojenik diyet tedavisi eğitim programı sirasında KDT'nin endikasyonları ve kontrendikasyonları, hasta ebeveynlerinin diyet tedavisinden beklentileri, yemek hazırlama ve pişirme teknikleri, gram ölçeğinin kullanımı, beslenme durumu ve kullanması gereken ürünlerle ilgili bilgi verilmiştir (6). Hastanın ebeveynlerinin onayından sonra, hasta 51 günlükken ketojenik diyet tedavisi başlanmıştır. Ketojenik diyet tedavilerinde hesaplamada yardımcı olmak için Charlie Vakfı'nın (Charlie Foundation) hazırladığı web tabanlı "Ketodietcalculator" programı kullanılmıştır (7).

Ketojenik diyet tedavisinin başlangıç aşamasında, her gün bir öğün KDT menüsü eklenerek bir hafta içerisinde tam KDT’ye geçilmiştir. John Hopkins Hastanesi Protokolü KDT yağlılık oranı 1.01:1 olacak şekilde değişiklik yapılarak uygulanmıştır (6). Hastanın normal menüsü anne sütü olmadığı için 60 mL suya 1 ölçek Aptamil 1 bebek maması ve 7 g Basic P mama karışımı verilecek şekilde hazırlanmıştır.

Tam ketojenik diyete geçildikten sonra günde 8 kez 50 mL suya 5 g Basic P mama ve 3 g KetoCal 4:1 mama karışımı hazırlanmıştır (Tablo 1). Hastamızın beslenmesi nazogastrik tüple sağlandı. Ketojenik diyet tedavisine ek olarak hastamızın gereksinim duyduğu vitamin miktarı hesaplanarak karbonhidrat içermeyen multivitamin desteği yapılmıştır Kan şekeri ve kan ketonu sabah ve akşam aç karnına ölçülmüştür (normal kan şekeri= 60-100 mg/dL, normal kan ketonu= 4-6 mol/L). 
Hastanın diyet tedavisinin 3. gününde albümin değerinin düşük çıkması ve nöbet sayısının artması nedeni ile KDT'nin yağlllık oranı 2.11:1 ve diyetin protein miktarı $1.48 \mathrm{~g} / \mathrm{kg} /$ gün olarak artırılmıştır. Kan ketonu 1-2 mmol/L düzeyinde seyretmiştir. Hastanın diyet tedavisi günde $7 \mathrm{kez} 50 \mathrm{~mL}$ suya $2 \mathrm{~g}$ Basic $\mathrm{P}$ mama, 6 g KetoCal 4:1 mama karışımı verilecek şekilde planlanmıştır (Tablo 1).

Ketojenik diyet tedavisinin 5. gününden itibaren hastanın bir saat içerisinde gözlenen nöbet sıklığı $\% 80$ azalmıştır. Hastanın kan ketonu 2-4 mmol/L olarak ölçülmüştür. Olgu halen levetirasetam (60 mg/kg/gün), fenobarbital ( $5 \mathrm{mg} / \mathrm{kg} / \mathrm{gün}$ ) ve sodyum benzoat (500 $\mathrm{mg} / g u ̈ n)$ kullanmaktaydı. Ketojenik diyet tedavisinin 10. gününde hastanın nöbet sayısının önemli derecede azalması (1-2 nöbet/gün) ve durumunun stabil olması sonucu hasta taburcu edilmiştir. Hastanın izlemi haftalık telefon görüşmeleri ve aylık çocuk nöroloji ve çocuk metabolizma poliklinik kontrolü ile yapılmıştır.

Birinci ay kontrolünde yapılan tetkiklerde hemoglobin (Hb) düzeyi $9 \mathrm{~g} / \mathrm{dL}$ olması nedeni ile diyet tedavisine karbonhidrat içermeyen demir preparatı eklenmiştir ve kan albümin değerinin (2.6 g/dL) (normal değeri= 3.2-4.6 g/dL) düşük olması nedeniyle diyetin protein miktarı $1.89 \mathrm{~g} / \mathrm{kg} /$ gün olarak arttırılmıştır. Diyetin yağlılık oranı 1.9:1 olarak düzenlenmiştir.
Kan ketonu 3-4 mmol/L arasında olduğu saptandl. Önerilen vitamin desteğini almakta zorlanması nedeniyle başka karbonhidrat içermeyen preperat bir ürün önerilmiştir. Birinci ay kontrolünde 3-4 gün nöbetsizlik, diğer günlerde 3-4 nöbet ve nöbet şiddetinin 1-10 dk arasında sürdüğü belirtilmiştir. Uygulanan epilepsi ilaç tedavisinde değişiklik yapılmamıştır. KDT'si, günde $7 \mathrm{kez} 85 \mathrm{~mL}$ suya $3 \mathrm{~g}$ Basic P mama ve 8 g KetoCal 4:1 mama karışımı verilecek şekilde hazırlanmıştır (Tablo 1).

İkinci ay kontrolünde hasta ebeveyni, son bir haftadır hastanın epilepsi ilaçlarını kustuğunu, mamayı ise kusmadığını belirtmiştir. Uyku halinin azaldığı ve günde 3-4 kez yüksek seste tetiklenen sıçrama nöbetlerinin olduğu belirtilmiştir. Hastanın evde ailesinin ölçtüğü kan ketonu ortalama 4-5 mmol/L olarak ölçülmüştür. KDT’si, günde $7 \mathrm{kez} 80 \mathrm{~mL}$ suya 4 g Basic P mama, 8 g KetoCal 4:1 mama, 1 g zeytinyağ karışımı verilecek şekilde hazırlanmıştır (Tablo 1).

Üçüncü ay kontrolünde hasta ebeveyni, bebeğin günde 1 kez 7 dk süren hıçkırık ve ağlama nöbetlerinin olduğunu ve günlük hareketlerinde artış olduğunu belirtmiştir. Hastanın kan albümin düzeyi $3.6 \mathrm{~g} / \mathrm{dL}$ olarak ölçüldü. KDT’si, günde 7 kez $120 \mathrm{~mL}$ suya $4 \mathrm{~g}$ Basic P mama, 10 g KetoCal 4:1 mama, 3 g zeytinyağ karışımı verilecek şekilde düzenlenmiştir (Tablo 1).

Tablo 1. Hasta için planlanan diyet içeriği ve klinik izlemi

\begin{tabular}{|c|c|c|c|c|c|c|c|c|}
\hline $\begin{array}{l}\text { Yaş } \\
\text { (ay/gün) }\end{array}$ & KDT (gün) & $\begin{array}{l}\text { KDT } \\
\text { oranı }\end{array}$ & $\begin{array}{c}\text { Enerji } \\
\text { (kkal/kg/ } \\
\text { gün) }\end{array}$ & $\begin{array}{l}\text { Proteini } \\
\text { (g/kg/gün) }\end{array}$ & $\begin{array}{c}\text { Vücut } \\
\text { ağırlığı (kg) }\end{array}$ & $\begin{array}{c}\text { Kan ketonu } \\
\text { (mmol/L) }\end{array}$ & $\begin{array}{c}\text { Nöbet } \\
\text { türü/sıklığı }\end{array}$ & $\begin{array}{c}\text { Plazma } \\
\text { glisin } \\
(\mathrm{mol} / \mathrm{L})\end{array}$ \\
\hline $45 / 365$ & $\begin{array}{l}\text { Tanı sonrası } \\
\text { düzenlenen } \\
\text { diyet tedavisi }\end{array}$ & $0.47: 1$ & 135 & 1.0 & 3.8 & $1-2$ & $\begin{array}{l}\text { Myoklinik ve } \\
\text { infantil spazm } \\
\text { (40 kez/gün) }\end{array}$ & 1035.0 \\
\hline $52 / 365$ & 1. gün & $1.01: 1$ & 101 & 0.9 & 3.8 & $2-4$ & 20 kez/gün & 613.5 \\
\hline $54 / 365$ & 3. gün & $2.11: 1$ & 98 & 1.48 & 4.05 & $2-4$ & 10 kez/gün & - \\
\hline $60 / 365$ & 9. gün & $2.11: 1$ & 98 & 1.48 & 4.05 & $4-5$ & 5-10 kez/gün & - \\
\hline $100 / 365$ & 30. gün & 1.9:1 & 117 & 1.89 & 4.25 & $4-5$ & Gün aşırı 1 kez & 334.4 \\
\hline $122 / 365$ & 60. gün & $2.02: 1$ & 119 & 1.61 & 5.0 & $4-5$ & Gün aşırı 1- 2 kez & 101.2 \\
\hline $156 / 365$ & 90. gün & $2.36: 1$ & 124 & 1.58 & 6.4 & $4-5$ & Gün aşırı 1- 2 kez & 321.0 \\
\hline
\end{tabular}




\section{TARTIŞMA}

Ketojenik diyet, yüksek yağ ve düşük karbonhidrat içeren bir beslenme tedavisidir. NKH ve erken myoklinik ensefalopatili hastaların tedavisinde KD tedavi seçeneği olarak denenmiştir (4,5). Hastanın plazma glisin düzeyi, sodyum benzoat ve dekstrometorfan tedavisiyle normale düşmüş, ancak ciddi dirençli nöbetleri devam etmiştir. Daha önce literatürde KDT’nin NKH'deki etkinliğini gösteren iki çalışma referans alınarak $(4,5)$ bu hastada KDT denenmiştir. Yapılan bir çalışmada 3 $\mathrm{NKH}$ hastasında farmokolojik tedaviyle birlikte KD tedavisi uygulanmıştır. Hastaların nöbet sıklığında ve şiddetinde azalmalar görülmüştür (4). Yakın zamandaki bir vaka raporunda da, KDT'nin 6 haftalık küçük bebeklerde dahi güvenli ve etkili olduğu gösterilmiştir (8).

Ketojenik diyet tedavisi, ilaca dirençli epilepsisi olan çocuklar ve yetişkinler için düzenlenen, farmakolojik olmayan bir tedavi yöntemidir. KDT başlanacak olan hastaların ön beslenme değerlendirmesi ve danışmanlığıçokdikkatliyapılmalıdır(6). Kliniğimizde tedavi gören dirençli epilepsi hastalarında, hasta ebeveyni ve KDT ekibi arasındaki düzenli iletişimin, KDT’nin etkinliğini ve uygulama süresini artırdığı gözlenmiştir. Hastanın taburculuk sonrası KDT kontrolleri her hafta telefon ve mesajlaşma yoluyla yapılmıştır. KDT’ye bağlı ciddi bir komplikasyonla karşılaşılmaması durumu, hasta ebeveynleri ve KDT ekibi arasındaki iletişimin kuvvetli olmasından kaynaklandığını göstermektedir. Uluslararası ketojenik diyet çalışma grubunun güncellenmiş önerilerinde, $\mathrm{KD}$ tedavisinde rutin görüşmelerin dışında diyet tedavisinin ilk haftalarında ve diğer rutin kontrollerde KD tedavi ekibi, aile ile telefon veya e-mail yoluyla iletişimde olması önerilmektedir (6).

Hastanın KDT yağ oranı 1.01:1 olarak başlandığında, ilk 2 gün keton düzeyinin yükselmesinde sorun yaşanmış, ancak KDT’nin 3. gününde diyetin yağ oranı 2.11:1 ve öğün sayısı 8'den 7’ye düşüldüğünde, kan keton düzeyinin yükselmesi ile birlikte nöbet sayısında ve şiddetinde azalma gözlenmiştir. Plazma glisin ve albümin düzeylerine göre hastanın diyetinin protein miktarı belirlenmiştir.

Ketojenik diyet tedavisinin üçüncü ayında hastanın nöbetlerinde \%85 oranında ciddi şekilde azalma olduğu gözlenmiştir. Ayrıca tedavinin ikinci ayından itibaren hastanın uyku eğiliminin azalması sonucu, çevreye karşı ayına uygun tepkilerin arttığı, ağlama ve hıçkırık nöbetleri sıklığının azalması ile anne ve bebek arası daha iyi bir iletişimin kurulduğu gözlenmiştir.

Sonuç olarak KDT, NKH hastalarında etkili ve güvenli bir tedavi yöntemi olabilir. Ancak etkinliği ve güvenirliğini desteklemek için daha fazla sayıda hastanın dahil olduğu çalışmalara gereksinim vardır..

Çıkar çatışması - Conflict of interest: Yazarlar çıkar çatışması olmadığın beyan ederler. - The authors declare that they have no conflict of interest.

\section{KAYNAKLAR}

1. Applegarth DA, Toone JR. Nonketotic hyperglycinemia (glycine encephalopathy): Laboratory diagnosis. Mol Genet Metab. 2001:74:139-46.

2. Swanson MA, Coughlin CR, Scharer GH, Szerlong HJ, Bjoraker KJ, Spector EB, et al. Biochemical and molecular predictors for prognosis in nonketotic hyperglycinemia. Ann Neurol. 2015;78:606-18.

3. Jacken J, de Koning T, van Hove J. Disorders GABA, glycine, serine and proline. In: Blau N, Duran M, Blaskovics ME, Gibson KM, editors. Physician's Guide to the Laboratory Diagnosis of Metabolic Diseases. 2nd ed. Berlin:Springer; 2002. p.123-40.

4. Cusmai R, Martinelli D, Moavero R, Dionisi Vici C, Vigevano F, Castana C, et al. Ketogenic diet in early myoclonic encephalopathy due ton on ketotic hyperglycinemia. Eur J Pediatr Neurol. 2012;16:509-13.

5. Bzduch V, Behulova D, Kolnikova M, Payerova J, Fabriciova K. Ketogenic diet in nonketotic hyperglycinemia. J Inherit Metab Dis. 2010;33(S1):S31.

6. Kossoff E, Zupec-Kaniz B, Auvin S, Ballaban-Gil KR, Christina Bergqvist AG, Blackford R, et al. Optimal clinical management of children receiving dietary therapies for epilepsy: updated recommendations of the international ketogenic diet study group. Epilepsia Open. 2018;3(2):175-92. 
7. Charlie Foundation for Ketogenic Therapies. Keto Diet Calculator. Available at: https://www.ketodietcalculator. org. Accessed February 10, 2019.
8. Thompson L, Fecske E, Salim M, Hall A. Use of the ketogenic diet in the neonatal intensive care unit - Safety and tolerabity. Epilepsia. 2017;58:e36-e39. 